\title{
CONTAMINACIÓN DE OPERARIOS CON CLORPIRIFOS, POR PRÁCTICA DE "EMBOLSADO" DE BANANO (Musa sp.) EN URABÁ, ANTIOQUIA
}

\author{
Juan Camilo Aguirre-Buitrago \\ Sandra Carolina Narváez-González \\ María Elena Bernal-Vera \\ Elmer Castaño-Ramírez
}

Recibido el 15 de julio de 2013 y aprobado el 9 de octubre de 2013

\section{RESUMEN}

Introducción: Teniendo en cuenta el daño potencial que se genera en la salud humana en la región de Urabá (Antioquia, Colombia) a través de la utilización de agrotóxicos, con énfasis en clorpirifos, se realizó esta investigación donde se evalúan los niveles de contaminación de los operarios expuestos al insecticida contenido en la bolsa de campo empleada en el cultivo de banano. Metodología: Este trabajo descriptivo se llevó a cabo mediante la obtención de muestras de sangre a los trabajadores de las fincas seleccionadas. Se registraron los niveles de colinesterasa eritrocítica y la prevalencia de sintomatología asociada con la exposición a plaguicidas con énfasis en organofosforados. Mediante encuestas se obtuvo información demográfica, socioeconómica y laboral y se caracterizó la exposición individual y ambiental. Resultados: Se determinó que es una población joven (entre 20 y 40 años) con falencias en sus sistemas de protección a través de un vestido de labor que deja áreas expuestas. $80 \%$ de los embolsadores de una de las fincas han presentado alteraciones en su nivel de colinesterasa comparada con las otras analizadas, lo que demandaría una especial mirada ambiental y de procesos. La sobreexposición laboral a agrotóxicos (11 años de exposición promedia) debida a la especialización de trabajadores que manipulan además otros productos con otras categorías toxicológicas, demanda vigilancia epidemiológica integral de estos obreros y su actividad. Son numerosas las personas intervinientes en la ruta tóxica que sigue la bolsa impregnada con clorpirifos sin que se les hagan los chequeos mínimos de seguimiento sanitario.

\section{PALABRAS CLAVE}

Colinesterasa, intoxicación, plaguicidas.

\section{CONTAMINATION OF WORKERS WITH CHLORPYRIFOS, DUE TO "BANANA (Musa sp.) BAGGING TECHNIQUE" IN URABÁ (ANTIOQUIA, COLOMBIA)}

\section{ABSTRACT}

Introduction: Considering the potential harm to human health that is generated in the Urabá region (Antioquia, Colombia) through the use of agro-toxic chemicals with emphasis in chlorpyrifos, this research was conducted in order to assess levels of contamination of workers exposed to insecticide contents in field bags used in banana crops. Methodology: This descriptive study was conducted obtaining blood 
samples from workers in selected farms. Erythrocyte cholinesterase levels and the prevalence of symptoms associated with exposure to organophosphate pesticides with emphasis on organophosphorous were recorded. Demographic, socioeconomic and employment information was obtained and individual and environmental exposure was characterized. Results: It was determined that it is a young population (between twenty and forty) with gaps in their protection systems through a work dress that leaves areas exposed; $80 \%$ of the baggers of one of the farms have presented alterations in their cholinesterase level compared to the other analyzed, which would require special environmental and process supervision. Occupational overexposures to agro-toxic chemicals (average 11 years of exposure) due to the specialization of workers who handle other products with other toxicological categories demand comprehensive epidemiological surveillance of these workers and their activity. There are numerous people involved in the toxic route followed by bags impregnated with chlorpyrifos without having had the minimal health monitoring checkups.

\section{KEY WORDS}

Cholinesterase, poisoning, pesticides.

\section{INTRODUCCIÓN}

En Colombia, el modelo de desarrollo agrícola se sustenta principalmente en el uso de agroquímicos con usos sin la necesaria investigación técnica. Se omiten, la mayoría de las veces, las precauciones debidas al conjunto de las características regionales como la variación del clima, la diversidad de las especies y la heterogeneidad de las culturas (Varona et al., 2007).

Las intoxicaciones causadas por plaguicidas son un problema central en salud pública, por la abundancia de químicos que los constituyen, y las múltiples aplicaciones en las actividades de la vida diaria basadas en más de 900 principios activos reconocidos a escala mundial como agrotóxicos, empleados en forma simultánea o secuencial en la misma zona, con una prolongada persistencia en el medio ambiente, y se constituyen en una importante fuente de contaminación. Por este motivo, la población se encuentra en un íntimo contacto con estos compuestos que pueden estar presentes en suelo, aire, agua o alimentos. La exposición ocupacional también constituye un tema de gran preocupación a escala mundial, debido a que la aplicación de los agrotóxicos generalmente está ligada a los riesgos para la salud por la aplicación de mezclas complejas de variados tipos de sustancias químicas (Hurtado \& Gutiérrez, 2005).

Las intoxicaciones agudas por organofosforados, son especialmente frecuentes en las zonas agrícolas, donde estos tóxicos se usan de forma habitual; destacando en este grupo el clorpirifos, que está en la lista de sustancias químicas reguladas por la Ley de Planeación para Emergencias y del Derecho a Saber de las Comunidades desde 1986 (The Emergency Planning and Community Right-toKnow Act of 1986, EPCRA, por sus siglas en inglés). Esto exige a 
los propietarios y operadores de las empresas que fabrican, importan, procesan o usan las sustancias químicas de esta lista, que notifiquen anualmente las emisiones de estas sustancias a cualquier tipo de medio ambiente. El clorpirifos es considerado una sustancia química peligrosa y está sujeto a regulaciones en la Ley de Agua Limpia y la Ley Federal de los Estados Unidos de Control de Contaminación de Agua. La Agencia de Protección Ambiental de Estados Unidos (EPA) ha establecido niveles límites de tolerancia para el clorpirifos en las materias primas para la agricultura y los alimentos para seres humanos y animales (Agencia de Sustancias Tóxicas y el Registro de Enfermedades -ATSDR-, 1997).

La regulación de los plaguicidas en Colombia ha estado enmarcada en medidas de regulación directa (o de comando y control) por parte del Estado, y han obedecido a la influencia de medidas similares que se han tomado en algunos países desarrollados, como los Estados Unidos, pero sin tener en Colombia la misma capacidad de regulación y control. En este país con el Decreto 3518, de octubre 9 de 2006, se crean y reglamentan los Sistemas de Vigilancia de Salud Pública -Sivigila-, para la provisión en forma sistemática y oportuna, de información sobre la dinámica de los eventos que afecten o puedan afectar la salud de la población, con el fin de orientar las políticas y la planificación en salud pública; tomar las decisiones para la prevención y control de enfermedades y factores de riesgo en salud; optimizar el seguimiento y evaluación de las intervenciones; racionalizar y optimizar los recursos disponibles y lograr la efectividad de las acciones en esta materia, propendiendo por la protección de la salud individual y colectiva (Decreto 3518 de 2006).

\section{Sector bananero}

En la zona de Urabá, según registros de AUGURA (Asociación de Bananeros de Colombia), existen 344 fincas o unidades de producción sembradas, con tamaño entre 20 y 170 hectáreas (promedio 71 hectáreas por finca). En la zona del Magdalena 77,7\% del área cultivada corresponde a fincas con extensión menor de 10 hectáreas, con pequeños productores (1.100) de bajo nivel tecnológico y de menor nivel competitivo en relación con las fincas de mayor tamaño relacionadas principalmente con las comercializadoras (Espinal, Martínez \& Peña, 2005).

Esta agroindustria en Urabá opera con una tipología de productor mediano y grande, tecnificados, con alto grado de integración vertical entre productores y comercializadoras. Actualmente las empresas transnacionales no participan directamente de la producción, ya que compran la fruta bajo contrato a las cooperativas o corporaciones que agrupan a los productores. Las transnacionales se dedican exclusivamente a la exportación comercial del producto. Este mecanismo es comúnmente usado en América Latina, donde además de las tres grandes transnacionales estadounidenses Chiquita, Dole (Standard Fruit Company) y Del Monte, participan también el grupo Noboa en Ecuador con la marca Bonita, las empresas colombianas Banacol, Unibán y Probán y las multinacionales Fyffes (Irlanda), Geest (Gran Bretaña) y Jamaica Producer. Las comercializadoras filiales toman sus decisiones en 
sus respectivas casas matrices, por ejemplo Dole y Chiquita en Estados Unidos; Del Monte y Fyffes, en Londres, etc. (Velásquez \& Giraldo, 2005).

La agroindustria está integrada verticalmente desde la producción hasta la comercialización. Cuenta con dos fábricas de cajas de cartón, tres fábricas de polietileno y polipropileno, tres fábricas de sellos, cuatro astilleros, almacenes de insumos para los productores, servicio especializado de fumigación aérea en el control de la Sigatoka negra (Mycosphaerella fijiensis), manejo integral del sistema de transporte fluvial y marítimo, y la infraestructura de comercialización en el exterior para la distribución directa de la fruta en los países de destino (Espinal et al., 2005).

\section{Embolse de la fruta}

La práctica de cubrir los racimos de banano es muy antigua; durante siglos fue usada en las islas del Pacífico con materiales naturales como telas, yute y hojas de banano para proteger los racimos del frío y el sol para mejorar la calidad (Sierra, 1993). El desarrollo de la cobertura plástica se inició en Australia en 1955 con el uso de tubulares de PVC, que fue reemplazado muy pronto por fundas perforadas de polietileno de baja densidad (LDPE) por ser menos costosas. Esta práctica fue rápidamente extendida en la década 60 en todo el mundo bananero (Memorias Expoagricultura, 2001).

En la década 70 se incorporó el insecticida de la familia de los organofosforados Dursban 1\%, con nombre genérico "Clorpirifos", para la protección de plagas. Otra alternativa para el control de insectos es la "Corbata" tratada con Clorpirifos 1\% que se usa al mismo tiempo con la funda sin tratar (Memorias Expoagricultura, 2001). La funda Poly-D deriva su nombre de la marca "PolyDursban", que fue hasta 1996 la resina exclusiva para fabricar la funda tratada, producida por Dow Chemical que tenía la patente. La funda Poly-D debe contener $1 \%$ de Clorpirifos al momento del embolse para que sea eficaz. El clorpirifos se cataloga como uno de los insecticidas más usados para tratar los plásticos que se emplean en la producción bananera (Memorias Expoagricultura, 2001).

\section{Intoxicaciones causadas por plaguicidas organofosforados}

El envenenamiento por insecticidas organofosforados produce la fosforilación irreversible de la acetilcolinesterasa en las terminaciones nerviosas. La recuperación ocurre cuando una nueva enzima reemplaza a la inactivada por el organofosforado; la sustitución de la acetilcolinesterasa fosforilada puede tardar entre varios días o algunas semanas (Díaz \& Salinas, 2002). Entre los principales síntomas que aparecen como resultado de sobreexposición a estas sustancias son: náuseas, vómito, diarrea y dolor de cabeza. Como los organofosforados se absorben a través de la piel, el contacto cutáneo, puede, localmente, causar sudor y contracciones musculares involuntarias y puede llevar a otros efectos sistémicos de los descritos anteriormente (Amador \& Astorga, 2006).

\section{Clorpirifos [0,0-dietil 0-(3, 5, 5-tricloro-2-piridil fosforotioato)]}


El clorpirifos es un insecticida descubierto por The Dow Chemical Company (Dow Química) en 1962, constituyéndose en uno de los ingredientes activos más utilizados del mundo para formular productos para el control de plagas. Se emplea para proteger distintos cultivos agrícolas importantes, como maíz, cítricos, alfalfa, maní, entre otros, del ataque de insectos. Se registró por primera vez en 1965, y ha estado presente en el mercado durante más de 40 años. Hoy está registrado en más de 98 países de todo el mundo, incluyendo las naciones más desarrolladas. Dow Agro Sciences LLC (Indiana, EE.UU.) es el principal fabricante de clorpirifos. Asimismo, existen otras compañías en China, Dinamarca, India e Israel que también fabrican clorpirifos (Dow Agro Sciences, 1998).

Pertenece al grupo de los organofosforados, sintetizados inicialmente durante la Segunda Guerra Mundial como arma química que afecta al sistema nervioso. Los organofosforados interfieren la acción de la colinesterasa, una enzima que rompe un neurotransmisor cerebral crítico, lo que provoca una sobreestimulación nerviosa y varios síntomas tóxicos agudos. Entre los síntomas de envenenamiento están: dolores de cabeza, náuseas, mareos, salivación, sudoración, dificultad respiratoria, tos, rigidez en el pecho, visión borrosa y, en casos más graves, vómitos, diarrea, dolor abdominal y dificultad para hablar. Si se alcanzan niveles muy tóxicos se pueden producir convulsiones, coma e incluso la muerte. Entre los efectos crónicos están: dificultad para concentrarse y memorizar, desorientación, depresión grave, irritabilidad, confusión, dolor de cabeza, dificultad para hablar, reacción lenta a los estímulos, pesadillas, sonambulismo, y somnolencia o insomnio. También existen pruebas de estudios realizados con animales, de que la exposición crónica a niveles bajos de organofosforados afecta tanto al desarrollo como al funcionamiento neurológico de animales en crecimiento. Con estas pruebas, es posible defender que la exposición permanente a niveles bajos de organofosforados, afecta de forma adversa al desarrollo del sistema nervioso, y puede tener como consecuencias la disminución de la capacidad cognitiva, trastornos del comportamiento y otros déficits neurológicos (Amador \& Astorga, 2006).

El clorpirifos es un insecticida sólido blanco de apariencia cristalina y de aroma fuerte. No es muy soluble en agua, de manera que generalmente se mezcla con líquidos aceitosos antes de aplicarse a los cultivos. También se puede suministrar a los cultivos en forma de cápsulas. Se ha usado ampliamente en viviendas y en agricultura. En el hogar, se emplea para controlar cucarachas, pulgas, y termitas y en ciertos collares de animales domésticos para manejar pulgas y garrapatas. En agricultura, se utiliza en aspersión para controlar un gran número de plagas (ATSDR, 1997).

\section{Colinesterasa}

Es una enzima que en el cuerpo regula el sistema nervioso y ayuda a que trabaje apropiadamente. Los plaguicidas que pueden bajar la colinesterasa se llaman organofosforados y carbamatos. Ejemplos de plaguicidas organofosforados y carbamatos comúnmente usados 
son: Clorpirifos (Lorsban), Carbaril (Sevin), Diazinon (Imidan) (Telasky, 2007). En la mayoría de los casos, una reducción en la colinesterasa, de hasta $50 \%$, no causa enfermedad. Sin embargo, los trabajadores con niveles bajos de colinesterasa, corren el riesgo de enfermarse si continúan exponiéndose a los plaguicidas (Telasky, 2007).

Cuando se toma la muestra de sangre, se miden dos tipos de colinesterasa: del plasma y de los glóbulos rojos. El primer examen corresponde al nivel basal personal y cada examen, después de ese, se compara con este nivel basal para averiguar si hay algún cambio (Telasky, 2007):

- Si el nivel de colinesterasa ha bajado y se sospecha que ha sido sobreexpuesto a los plaguicidas, entonces se debe revisar el trabajo que realiza la persona.

- Si el nivel de colinesterasa está muy bajo, la persona debe ser retirada temporalmente de manipular plaguicidas y de otras posibilidades de ser expuesto, hasta que su colinesterasa regrese a un nivel seguro.

Los niveles de colinesterasa se detectan por dos razones:

- Si el nivel de colinesterasa de los glóbulos rojos o plasma baja más de $20 \%$ de su nivel basal, se debe revisar por parte de las empresas, cómo el trabajador manipula los pesticidas, averiguar cómo está siendo expuesto y hacer correcciones.

- Si el nivel de colinesterasa de los glóbulos rojos baja más de $30 \%$ o el nivel de colinesterasa de su plasma baja más de $40 \%$ de su nivel basal, el trabajador debe ser retirado de manipular pesticidas y de otras posibilidades de ser expuesto a pesticidas inhibidores de la colinesterasa (Telasky, 2007).

\section{Otros estudios que demuestran los riesgos en la salud por contacto con el clorpirifos}

Varias evidencias experimentales sugieren la existencia de un efecto genotóxico producido por la exposición aguda o crónica a algunos pesticidas; sin embargo, la información sobre genotoxicidad en seres humanos expuestos a mezclas de los mismos es limitada, particularmente en niños. Varias publicaciones señalan que algunos de los mencionados plaguicidas causan mutaciones, aberraciones cromosómicas y daño sobre el $A D N$ en poblaciones ocupacionalmente expuestas. El biomarcador de genotoxicidad empleado con mayor frecuencia es el test de aberraciones cromosómicas (AC) en linfocitos de sangre periférica. Otro método empleado comúnmente es el ensayo de micronúcleos. Estos representan la presencia de fragmentos cromosómicos o cromosomas enteros que han sido excluidos del núcleo principal por causa de una división celular anormal por pérdida de la región central. Entre los agrotóxicos estudiados existen 28 que producen efecto genotóxico demostrable experimentalmente, 19 considerados probables cancerígenos categoría B2 por la Environmental Protection Agency (EPS). Sin embargo, es de destacar que este resultado es producto del análisis del efecto producido por cada uno de los agrotóxicos en forma aislada o combinada en hepatocitos de 
rata por medio del test de micronúcleos. Los investigadores observaron que ninguno de los compuestos utilizados evidenciaba un efecto genotóxico aplicado en forma aislada, pero detectaron un significativo aumento en la frecuencia de micronúcleos al utilizarlos en forma combinada (Monterroso \& Ferreira, 2006).

Se destacan los efectos del clorpirifos sobre el sistema nervioso de trabajadores bananeros en La Lima (Honduras) en 2003. SITRATERCO (Sindicato de Trabajadores de la Tela Railroad Company), denunció problemas de salud en embolsadores bananeros en La Lima (Honduras). Estos habían colocado diariamente 150 bolsas de polietileno impregnadas con clorpirifos alrededor de la fruta, con equipo de protección completo, durante 315 meses. Se analizaron los datos de 96 trabajadores menores de 50 años seleccionados al azar de las 10 fincas bananeras afiliadas al sindicato, 48 protegedores expuestos y 46 controles (24 de campo y 22 empacadores). Todos los protegedores, menos dos, tenían residuos detectables del metabolito 3,5,6-tricloro-2-piridinol (TCP) en orina (mediana $161 \mu \mathrm{g} / \mathrm{g}$ creatinina) frente a 1 control. Se midió la exposición dérmica en manos, antebrazos y área peribucal en tres embolsadores, encontrando residuos detectables en estas áreas. Los embolsadores, tenían colinesterasas plasmáticas y eritrocitarias significativamente más bajas que los controles. Los embolsadores presentaron más síntomas típicos de intoxicación aguda con organofosforados que los controles (Wesseling et al., 2005).

En el sur de Chile fue visible la intoxicación por plaguicidas que sufrieron 60 trabajadoras y 13 trabajadores agrícolas temporeros mientras recolectaban manzanas. Todos sufrieron náuseas, principio de asfixia, vómitos y picazón al ingresar al predio de la empresa Agrícola y Comercial Santa Elena, en la ciudad de Angol, 600 kilómetros al sur de Santiago, que días antes había sido fumigada con el insecticida Lorsban 75 WG y el fertilizante foliar Wuxal Calcio. El Ministerio de Salud de Chile notificó 471 intoxicaciones agudas por plaguicidas (de octubre a abril), con tasa de 2,9 por cada 100 mil habitantes. $57 \%$ de los casos fueron de origen laboral $\mathrm{y}$, de estos, $81 \%$ de obreras y obreros agrícolas, de los cuales más de la mitad se ocupaban en labores de temporada (Estrada, 2005).

María Elena Rosas, coordinadora de la Red de Acción en Plaguicidas y sus Alternativas de América Latina (RAP-AL), advierte "que por cada caso notificado hay otros cuatro sin notificar, y en algunas regiones del norte y del sur hay 10 más, lo que significa dos mil 500 a tres mil personas afectadas por año". (Estrada, 2005)

En 2000, el Servicio Agrícola y Ganadero (SAG) del Ministerio de Agricultura, encargado de la normativa y fiscalización de los agroquímicos:

[...] clasificó al Lorsban 75 WG como "poco peligroso" considerando sus efectos agudos, aunque RAP-AL, Anamuri, la Corporación de 
Investigación en Agricultura Alternativa y el Observatorio Latinoamericano de Conflictos Ambientales afirman que la exposición al mismo provoca graves dolencias a largo plazo. [...] los trabajadores tienen el derecho de conocer tanto los efectos inmediatos como a largo plazo, los cuales deberían estar especificados claramente en la etiqueta. [...] Según datos de la estatal Oficina de Estudios y Políticas Agrarias, en 1997 Chile importó 16 mil 68 toneladas de plaguicidas, mientras que en 2003 las compras aumentaron a 22 mil 218 toneladas. Chile es uno de los mayores exportadores de frutas y hortalizas de América Latina, con cosechas que generan una importante proporción de empleo temporal, cubierto mayoritariamente por mujeres. En el agro chileno trabajan 800 mil personas, la mitad de las cuales son temporeras, y de ellas 250 mil son mujeres, a las que se suman adolescentes, niñas y niños. (Estrada, 2005)

Los lineamientos de política en especial los contemplados en el Decreto 1843 de 1991, deben permitir necesariamente que las empresas productoras e importadoras de plaguicidas, las empresas prestadoras de servicios (transporte, distribuidores y aplicadores) y los usuarios de estos productos, desarrollen nuevas alternativas de control y manejo ambiental que impliquen un menor riesgo para la salud humana y el ambiente. Al desarrollar estos programas, se puede "iniciar un conjunto de actividades o medidas tendientes a evitar la presencia de la intoxicación por plaguicidas, como evento epidemiológico y al observar el comportamiento del mismo en un futuro, evaluar las medidas de intervención a implementar" (Hurtado \& Gutiérrez, 2005, p. 256).

Desde estas perspectivas y teniendo en cuenta el daño potencial que se genera en la salud humana en la región de Urabá (Antioquia) a través de la utilización de agrotóxicos, con énfasis en el uso del ingrediente activo clorpirifos, se realizó la presente investigación donde se evalúan los niveles de contaminación de los operarios expuestos al insecticida de nombre comercial más común Lorsban ( $48 \%$ EC y $2,5 \%$ DP), contenido en la bolsa de campo empleada en el cultivo de banano (una de las prácticas agrícolas utilizadas para la protección de la fruta en las fincas bananeras de toda la región); y se cumplen los siguientes objetivos específicos:

- Caracteriza la población más vulnerable a la contaminación por agrotóxicos en las plantaciones.

- Establece el efecto acumulado de otros agrotóxicos usados en la explotación de banano y que pueden alterar la colinesterasa en labores del cultivo.

- Determina el tiempo de exposición a insecticidas durante la vida laboral de cada operario.

- Describe la ruta de exposición a la contaminación causada por el uso y la manipulación de la bolsa de campo impregnada con clorpirifos. 
- Identifica los productos que han sido retirados de la explotación en los últimos dos años y que podrían guardar relación con alteraciones de la colinesterasa.

\section{METODOLOGÍA}

\section{Ubicación y fecha del estudio}

Este trabajo, se llevó a cabo en los municipios de Chigorodó, Carepa y Nueva Colonia (Turbo), ubicados en la región de Urabá, en el departamento de Antioquia, lugares donde se concentra $70 \%$ de las exportaciones colombianas de la producción de banano tipo exportación. La zona de estudio está a nivel del mar, su clima es cálido-húmedo tropical, con niveles de humedad de hasta $80 \%$ y altos niveles de precipitación, dedicada casi por completo al cultivo del banano y plátano. Los valores de precipitación oscilan entre 2251 y 4250 mm/año. Es muy frecuente el uso de plaguicidas por aspersión y por fumigación aérea. Para el desarrollo de este trabajo, se seleccionó una finca por cada municipio y en cada una de estas se corrieron las encuestas y se tomaron las muestras de sangre, al personal previamente seleccionado.

El trabajo de campo se llevó a cabo entre junio y agosto del año 2009 , en el que se evaluaron las muestras de sangre de operarios y del grupo técnico y se compararon con resultados históricos. En la Tabla 1 se clasifican por labor:

Tabla 1. Clasificación de los participantes del estudio

\begin{tabular}{|c|c|c|c|c|c|}
\hline $\mathbf{N}^{0}$ & TRABAJADOR & LABOR & $\mathrm{N}^{0}$ & TRABAJADOR & LABOR \\
\hline 1 & A1 & Embolsador & 13 & C1 & Embolsador, Fumigador \\
\hline 2 & A2 & Embolsador & 14 & $\mathrm{C} 2$ & Embolsador, Fumigador \\
\hline 3 & $\mathrm{~A} 3$ & Embolsador, Fumigador & 15 & C3 & Embolsador \\
\hline 4 & A4 & Fumigador & 16 & $\mathrm{C} 4$ & Embolsador \\
\hline 5 & A5 & Embolsador & 17 & C5 & Embolsador \\
\hline 6 & B1 & Embolsador & 18 & C6 & Embolsador \\
\hline 7 & B2 & Embolsador & 19 & C7 & Embolsador, Fumigador \\
\hline 8 & B3 & Embolsador & 20 & D1 & Administrador \\
\hline 9 & $\mathrm{~B} 4$ & Embolsador & 21 & D2 & Manejo ambiental \\
\hline 10 & B5 & Embolsador & 22 & D3 & Manejo fertilización \\
\hline 11 & B6 & Embolsador & 23 & D4 & Manejo riegos y drenajes \\
\hline 12 & B7 & Embolsador & & & \\
\hline
\end{tabular}

\section{Población}

La población elegida fueron los trabajadores que realizan la labor de embolse en las fincas bananeras y permanecen en contacto directo con el clorpirifos, como ingrediente activo de estas bolsas empleadas para proteger el banano del ataque de plagas. Con fines comparativos se eligió otro grupo de personas quienes no se encuentran en permanente contacto con el clorpirifos, pero que se hallan expuestas a los agrotóxicos que se utilizan en la región de 
Urabá, especialmente a las fumigaciones aéreas, aplicación de herbicidas, y a los productos utilizados en el tratamiento poscosecha de la fruta (ingenieros, administradores y técnicos). En el trabajo de campo participaron 23 personas, todos adultos. El mayor número de trabajadores (11 de 23 ) se encontraban entre 20 y 30 años de edad $(46 \%)$, le siguen los que estaban entre 31 y 40 años (6, 27\%), cinco $(22 \%)$ de 41 a 50 y solo una persona era mayor de 51 ; no había menores de 18 años.

\section{Recopilación de la información}

Se realizó mediante 23 encuestas con las que se obtuvo: información demográfica, socioeconómica y laboral; se documentó el estado de salud de la población estudiada y se caracterizó la exposición laboral y ambiental. Se estudiaron las hojas de vida, historial clínico y se hizo un análisis de sangre. A través de la unidad médica se practicó la toma de sangre en horas de la mañana y en condiciones de asepsia del lugar y con desinfección de la piel. Se extrajo la muestra de sangre mediante una punción venosa a cada participante, el cual debía estar en ayunas; la información se registró en un formulario y cada muestra fue almacenada y debidamente rotulada en tubos, para ser conservados en envases tecnopor. Una vez obtenidas todas las muestras se llevaron al laboratorio clínico UNLAB del municipio de Apartadó (Antioquia). El análisis de las muestras de sangre fue procesado por la Bacterióloga Luz Elena Ocampo Montoya y en condiciones del laboratorio clínico UNLAB, se empleó el método Michel implementado en la zona de Urabá por todos los centros de salud en convenio con las comercializadoras, para determinar los niveles de colinesterasa en los trabajadores del sector bananero. En Colombia, los valores de referencia de la colinesterasa se han tomado de estudios de países con características poblacionales, genéticas, biológicas, socioeconómicas y culturales muy diferentes del colombiano. Además, tales estándares han surgido de estudios con grupos muy pequeños no representativos de la población.

\section{Interpretación de resultados}

La interpretación de los resultados sobre la actividad de la colinesterasa se expresa en porcentaje, el cual oscila en un rango de $80 \%$ a $120 \%$, considerando como valores de referencia internacionales: valores normales para actividad de la colinesterasa: mayor de $80 \%$ de actividad; valores anormales: igual y menores de $80 \%$ de actividad, indicador de sangre contaminada, asumiendo que el rango $80 \%$ como límite es un indicador de un bajo riesgo de intoxicación.

\section{Acciones correctivas}

Teniendo en cuenta los resultados del laboratorio, se asume que las personas que se encuentren en un valor de colinesterasa mayor o igual a $80 \%$, continuarán desempeñándose en la labor de embolse, sin dificultades. En todos los casos donde el resultado de la actividad de la acetilcolinesterasa sea "anormal" (menor de 80\%) se procede a la reubicación inmediata del trabajador por cuatro meses, lapso en el que se debe realizar la siguiente prueba para determinar 
los niveles de colinesterasa. Se destaca que, en la región de Urabá, se realizan tres exámenes de colinesterasa al año, número establecido por los centros de salud que operan en la zona y cubren exclusivamente a los trabajadores que se desempeñan en la labor de embolse. Los estatutos de las normas que certifican el banano como fruta de exportación, exigen anualmente la valoración de los niveles de colinesterasa en los embolsadores quienes, se considera, presentan un mayor riesgo por el permanente contacto con las bolsas de campo y su ingrediente activo: el clorpirifos.

\section{RESULTADOS}

La protección del racimo mediante la labor del embolse se realiza dos veces por semana con el trabajador indicado, este ejercicio implica que el obrero de campo debe llevar los elementos de protección necesarios y recomendados por el departamento de salud ocupacional y las herramientas requeridas para el desarrollo del trabajo: escalera (se ubica en las plantas para realizar la labor); machetilla (se usa en campo para cortar las bolsas); bolsas (impregnadas $1 \%$ del peso de la bolsa con clorpirifos, para proteger el racimo); cintas (usadas para la identificación del racimo).

$52 \%$ (12 embolsadores) de los encuestados han estudiado básica secundaria, $17 \%$ (4 empleados) han cursado estudios superiores universitarios y $31 \%$ (7 embolsadores) tienen la básica primaria. El nivel de educación de estas personas les permite leer y entender con capacidad de comprensión los estatutos y normas establecidas en los sistemas de producción bananero. En general cuando las personas ingresan a trabajar en las comercializadoras, reciben una inducción sobre las políticas de la empresa y se les capacita en manejo de alimentos y seguridad personal. Quienes se dedican a la labor de embolse, reciben una capacitación al año acerca del manejo de agroquímicos, se les brinda los implementos de protección personal y se les vigila a través de los exámenes de colinesterasa la integridad de su salud. Frente a las capacitaciones de agroquímicos el cuerpo administrativo realiza pequeñas campañas para cumplir con los estándares de la norma, en la cual se informa de todo lo necesario a los operarios que manejan estos productos; sin embargo, $82 \%$ (19 embolsadores) de los encuestados no conocen los agroquímicos que se aplican en las fincas bananeras.

Los elementos de protección personal que son usados por los embolsadores en la plantación bananera de la región de Urabá son: sudadera, buzo de manga larga, guantes de nitrilo, botas de caucho. Se observó la disposición de cada uno de los elementos de protección y la manera como cada trabajador los lleva puestos, destacando que este traje se considera el uniforme oficial de la comercializadora representada con un símbolo en el lado izquierdo del buzo. Se busca con esto, generar una identidad propia de los trabajadores que laboran en el grupo de fincas que exportan su fruta bajo una misma comercializadora, lo cual establece un orden y una logística en la producción de la fruta; es decir, aunque existen diversos propietarios de estas fincas productoras de banano, es la 
comercializadora la que impone su marca en el mercado y consolida este grupo de fincas bajo un mismo concepto empresarial, orientados hacia el mismo objetivo.

El trabajador tiene la oportunidad de participar de otras labores en la producción del banano. En la Tabla 2 se representan las labores (adicionales al embolsado) más frecuentemente realizadas por quienes tienen el embolse como actividad central y donde igualmente tienen contacto con plaguicidas.

Tabla 2. Otras labores realizadas por los embolsadores

\begin{tabular}{|l|c|c|}
\hline \multicolumn{1}{|c|}{ LABOR } & $\begin{array}{c}\# \\
\text { TRABAJADORES }\end{array}$ & $\begin{array}{c}\text { PORCENTAJE DE LOS } \\
\text { EMBOLSADORES (\%) }\end{array}$ \\
\hline Embolsado & 20 & 74,1 \\
\hline Recibo de bolsa & 20 & 74,1 \\
\hline Rotura de bolsa & 5 & 18,5 \\
\hline $\begin{array}{l}\text { Manipulación del material } \\
\text { de desecho }\end{array}$ & 1 & 3,7 \\
\hline Desmane ylavado & 7 & 25,9 \\
\hline
\end{tabular}

Fuente: Ests investigsción.

La labor de embolse es realizada por 20 trabajadores $(74,1 \%)$, con esta como la labor principal, a través de la cual el operario tiene un mayor contacto con el clorpirifos contenido en cada una de estas bolsas de campo. El recibo de bolsa es una labor propia de la actividad (participan los mismos 20 trabajadores), puesto que cada uno debe dirigirse a la bodega donde se les entrega la cantidad de bolsas requeridas para el día, este ejercicio se hace dos veces diarias. El almacenista es la primera persona que recibe estas bolsas cuando ingresan a la finca y las acopia en la bodega, el contacto con este insumo es una labor obligada. Los elementos de protección de los almacenistas se basan en la utilización de una careta, guantes de nitrilo largo, camisa manga corta, pantalón y botas. Las bolsas de campo son entregadas por el almacenista a cada trabajador de manera personal.

La rotura de la bolsa, es una actividad realizada por cinco obreros $(18,5 \%)$ y consiste en quitar la bolsa que cubre el racimo cuando se encuentra en la empacadora para ser procesado en la etapa de poscosecha de la fruta. La manipulación del material de desecho, es realizada por quien debe recoger los residuos de bolsa que quedan al finalizar el proceso en las empacadoras, estos desechos se almacenan en canecas y se aíslan en una bodega. El desmane y lavado se realiza por siete operarios, y consiste en cortar las manos de los racimos que llegan a la empacadora para constituir los gajos de banano que finalmente se incluirán en una caja. Durante esta labor el trabajador no tiene contacto directo con el clorpirifos, pero sí con los fungicidas que se adicionan al tanque de mezcla en el que se lava la fruta.

$35 \%$ de los trabajadores evaluados ingieren algún tipo de bebida durante la labor, lo cual se considera una acción con alto riesgo de intoxicación, debido a que los operarios tienen las manos contaminadas por el uso de las bolsas y muy fácilmente pueden entrar en contacto con el agua que consumen. 
Como vínculo familiar, se denota $47 \%$ de la población en unión libre, $22 \%$ casados y $31 \%$ solteros. 17 personas de 23 (73\%) tienen promedio de dos hijos por familia. La observación sobre la salud de los hijos muestra que $6 \%$ estaban enfermos; $94 \%$ de los hijos de los embolsadores no manifiestan hasta el momento problemas en su salud. Se destaca un caso de un niño enfermo, de 8 años de edad, correspondiente a $6 \%$ de la población evaluada, con retraso mental desde el nacimiento. Como antecedentes, el padre del menor es un hombre joven de 30 años de edad, su vínculo familiar está constituido por dos hijos más de 4 y 9 años de edad. En su trabajo, se ha desempeñado en los sistemas de producción de banano por 14 años y lleva 12 años realizando la labor de embolse de la fruta, además del manejo constante de las bolsas de campo impregnadas con clorpirifos, ha manipulado otros plaguicidas, entre ellos herbicidas, y ha manifestado molestias en su salud como: dolor de cabeza, ardor en ojos, decaimiento, irritación y ardor en la piel. Estos síntomas normalmente se presentan después de realizar la labor.

En la historia clínica de este trabajador (A2) resaltan las variaciones de los valores de actividad de la colinesterasa en el tiempo. Tomando como referencia estos valores, se destaca que la salud de este trabajador ha presentado un descenso que se expresa en una de las pruebas realizadas y en dos de las siguientes pruebas los valores se encuentran en el límite, si se considera que $80 \%$ es el valor de partida en las pruebas de Michel.

Algunos de los síntomas más frecuentes que afectan a los embolsadores aparecen en los dos gráficos siguientes:

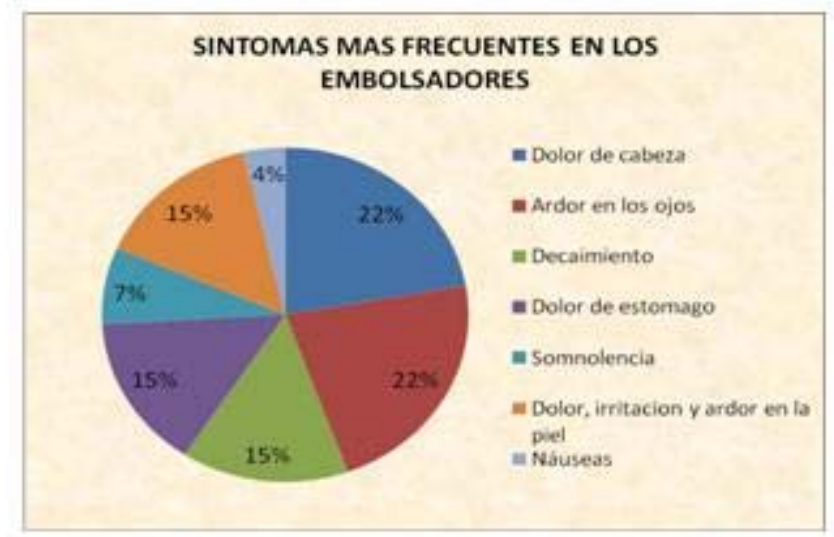

Fuente: Esta investigación.

Gráfico 1. Sintomas más frecuentes en los embolsadores. 


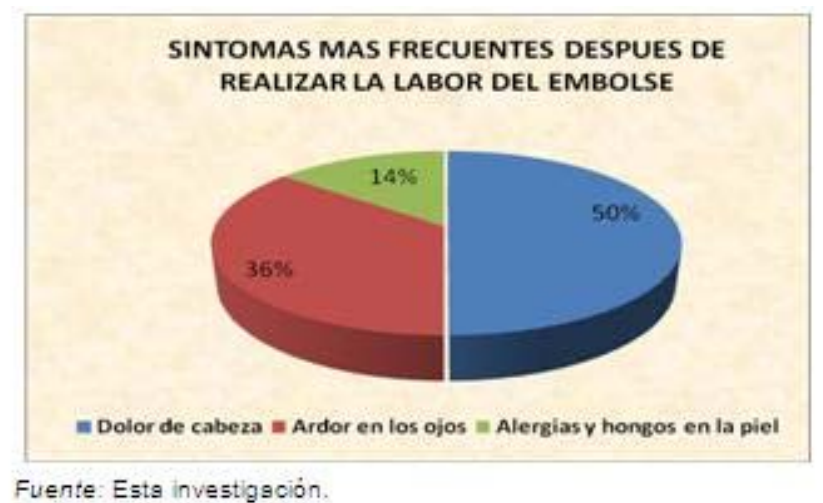

Gráfico 2. Síntomas más frecuentes después de realizar la labor del embolse.

Otros factores incidentes son: 1) El consumo de licor y la adicción al cigarrillo son factores que alteran los niveles de colinesterasa y se convierten en elementos tributarios de los descensos en su actividad. $70 \%$ de los embolsadores fuman en promedio cuatro cigarrillos al día. 2) La ubicación de las viviendas. 13\% (tres trabajadores de 23) tienen las casas en lugares por donde circulan los aviones de fumigación y donde las familias del trabajador y el mismo se encuentran en permanente contacto con los agroquímicos por efectos de deriva. 3) El consumo de fruta de rechazo no lavada es práctica de $100 \%$ de los trabajadores quienes la consumen diariamente y la llevan para el consumo familiar.

\section{Valoración de la actividad de la colinesterasa}

De acuerdo con el análisis de la actividad de la colinesterasa eritrocitaria en los exámenes de sangre realizada en los 23 asalariados del grupo de embolsadores de cada finca en estudio y el grupo técnico de apoyo de una misma comercializadora, 95\% presentan actividad de colinesterasa de bajo riesgo (superior a $80 \%$ de los parámetros normales de sangre para esta prueba), mientras que $5 \%$ restante exhibe alteraciones en los valores de referencia. En las siguientes tablas se muestran los resultados del porcentaje de colinesterasa eritrocitaria a través del tiempo, tomando como referencia los antecedentes clínicos de cada embolsador que participó de las pruebas durante esta investigación. Asimismo, se evalúa el tiempo de exposición al contacto con el clorpirifos que han tenido a lo largo de su vida laboral. Los valores aquí expuestos, datan del año 2008 y una prueba realizada en 2009. 
Tabla 3. Valores de colinesterasa eritrocitaria por fincas y por operario en seguimiento de 1,5 aก̃os

\begin{tabular}{|c|c|c|c|c|c|c|c|}
\hline \multirow{2}{*}{$\mathbf{N}^{\circ}$} & \multirow{2}{*}{ EMBOLSADOR } & \multirow{2}{*}{ EDAD } & $\begin{array}{l}\text { TIEMPO DE } \\
\text { EXPOSICION }\end{array}$ & \multicolumn{4}{|c|}{$\%$ COLINE STERASA ERITROCITARIA } \\
\hline & & & AÑOS & $05 / 02 / 08$ & $05 / 05 / 08$ & $15 / 12 / 08$ & $19 / 06 / 09$ \\
\hline 1 & A1 & 48 & 18 & 86,21 & 78,16 & 96.55 & 85,06 \\
\hline 2 & $\mathrm{~A} 2$ & 30 & 14 & 78,16 & 80,45 & 94,25 & 80.46 \\
\hline 3 & $\overline{A 3}$ & 41 & 7 & 77,01 & 80.45 & 88,50 & 81.51 \\
\hline 4 & A4 & 26 & 4 & 84,05 & 93,09 & 102,29 & 83,91 \\
\hline 5 & A5 & 54 & 20 & 68,28 & 80,45 & 84,70 & 82,76 \\
\hline \multicolumn{4}{|c|}{ EDIOS = } & 78,74 & 82.50 & 93.25 & 82.76 \\
\hline
\end{tabular}

\begin{tabular}{|c|c|c|c|c|c|c|c|}
\hline \multirow{2}{*}{$N^{*}$} & \multirow{2}{*}{ EMBOLSADOR } & \multirow{2}{*}{ EDAD } & $\begin{array}{c}\text { TIEMPO DE } \\
\text { EXPOSICION }\end{array}$ & \multicolumn{3}{|c|}{$\%$ COLINE STERASA ERITROCITARIA } \\
\cline { 4 - 8 } & & & ANOS & $01 / 02 / 08$ & $02 / 05 / 08$ & $12 / 12 / 08$ & $19 / 06 / 09$ \\
\hline 1 & $B 1$ & 44 & 10 & 94,25 & 89,10 & 88,30 & 89,66 \\
\hline 2 & $B 2$ & 40 & 10 & 82,75 & 86,20 & 81,62 & 80,30 \\
\hline 3 & $B 3$ & 29 & 10 & 80,20 & 77,10 & 81,20 & 78,16 \\
\hline 4 & 84 & 31 & 6 & 94,25 & 91,95 & 90,80 & 89,50 \\
\hline 5 & 85 & 34 & 1 & 85,20 & 81,50 & 90,80 & 90,00 \\
\hline 5 & $B 6$ & 34 & 11 & 83,10 & 87,20 & 90,80 & 80,00 \\
\hline 7 & 87 & 28 & 3 & 85,20 & 85,10 & 89,60 & 86,00 \\
\hline \multicolumn{7}{|l}{} \\
\hline
\end{tabular}

\begin{tabular}{|c|c|c|c|c|c|c|c|c|}
\hline \multirow{2}{*}{$\mathbf{N}^{\circ}$} & \multirow{2}{*}{ EMBOLSADOR } & \multirow{2}{*}{ EDAD } & $\begin{array}{l}\text { TIEMPO DE } \\
\text { EXPOSICION }\end{array}$ & \multicolumn{5}{|c|}{$\%$ COLINE STERASA ERITROCITARIA } \\
\hline & & & ANOS & $02 / 05 / 08$ & $01 / 0808$ & $02 / 1208$ & $11 / 03 / 09$ & $02 / 07 / 09$ \\
\hline 1 & C1 & 26 & 8 & 91,95 & 100,00 & 98,85 & 89,66 & 100,00 \\
\hline 2 & $\mathrm{C} 2_{2}$ & 50 & 25 & 95,40 & 90,50 & 87,35 & 83,91 & 83.20 \\
\hline$\frac{\pi}{3}$ & $\mathrm{C}_{3}$ & 41 & 17 & 80,45 & 82,75 & 80,46 & 82,75 & 82,76 \\
\hline 4 & $\mathrm{C}_{4}$ & 45 & 25 & 89,65 & 103,44 & 100,00 & 90,80 & 104.60 \\
\hline 5 & C5 & 36 & 10 & 83,90 & 83,90 & 82,20 & 82,75 & 90,80 \\
\hline 6 & C5 & 42 & 20 & 82,75 & 91,95 & 91,95 & 88,06 & 90,40 \\
\hline 7 & C7 & 25 & 4 & 85,05 & 97,79 & 95,40 & 92,70 & 102,30 \\
\hline \multicolumn{4}{|c|}{ PROMEDIOS = } & 87,02 & 92,90 & 90,89 & 87,23 & 93,44 \\
\hline
\end{tabular}

\begin{tabular}{|c|c|c|c|c|c|}
\hline \multirow[t]{2}{*}{$\mathrm{N}^{\circ}$} & \multirow{2}{*}{ TEECNICO } & \multirow[t]{2}{*}{ EDAD } & \multirow[t]{2}{*}{ PROFE SIÓN } & $\begin{array}{l}\text { TIEMPO DE } \\
\text { TRABAJO }\end{array}$ & $\begin{array}{l}\% \text { COLINE STERASA } \\
\text { ERITROCITARIA }\end{array}$ \\
\hline & & & & ANNOS & $17 / 09 / 2009$ \\
\hline 1 & D1 & 29 & Administrgdor & 5 & 80.46 \\
\hline 2 & $\mathrm{D} 2$ & 26 & Ingeniero Agrónomo & 2 & 93,10 \\
\hline 3 & D3 & 26 & Ingenierg Agropecuaria & 3 & 83,91 \\
\hline 4 & 04 & 25 & Ingenierg Ágronoms & 2 & 82,76 \\
\hline $\mathrm{PR}$ & MEDIOS = & & & & 85.05 \\
\hline
\end{tabular}

Fuente: Esta investigacion.

En negro se destacanlos valores pordebajode $80 \%$ y en gris los que se encuentran en el limite de referencia intemacional

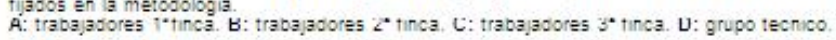

Seguimiento colinesterasa eritrocitaria, finca A. Finca ubicada en el municipio de Chigorodó (Antioquia), con extensión de 60 hectáreas y 34 trabajadores en total que manejan la producción de banano desde el campo hasta el llenado de las cajas, que son exportadas a diario a países europeos como Alemania y Bélgica. Los trabajadores embolsadores tienen contacto permanente con el clorpirifos presente en la bolsa de campo, empleada en la protección de la fruta. Se denotan niveles de colinesterasa alterados, en cuatro de cinco embolsadores a quienes se les practicó la prueba, con resultados por debajo de $80 \%$ o en niveles límite.

Seguimiento de colinesterasa eritrocitaria, finca B. Finca ubicada en el municipio de Carepa (Antioquia), cuenta con una extensión de 160 hectáreas y 80 trabajadores. De acuerdo con el historial de pruebas de colinesterasa realizadas, se declara un nivel normal de colinesterasa con porcentajes que superan $90 \%$ en seis de siete embolsadores. Se presenta un caso alterado y uno en el nivel límite. Se trata de un operario de 29 años de edad con 10 años de experiencia laboral, quien presenta historial clínico inconsistente, 
puesto que de cuatro valoraciones realizadas, la mitad presenta valores anormales $(77 \%$ y $78 \%)$ lo que corresponde a una disminución del volumen de la colinesterasa, potencialmente debido al desempeño de su labor.

Seguimiento de colinesterasa eritrocitaria, finca C. Finca ubicada en el municipio de Turbo (Antioquia), con extensión de 190 hectáreas y 90 trabajadores, de los cuales siete personas realizan la labor de embolse. El porcentaje de colinesterasa tiene comportamiento normal a través del tiempo, con valores de actividad de la colinesterasa en el límite, solo para un operario. Esta finca ha sido manejada durante los últimos tres años bajo los criterios de la norma Free trade, la cual hace referencia al comercio justo, motivando a los productores a invertir en el bienestar y calidad de vida de los trabajadores a través del incremento de un dólar por cada caja de banano que se produce en las fincas que adoptan esta modalidad. Teniendo en cuenta estas consideraciones, se genera en las comercializadoras una mayor conciencia en el cuerpo administrativo, sobre las condiciones laborales de los trabajadores; y estos a su vez adquieren una mayor cultura en el entorno de la producción bananera, lo cual hace que estas personas tengan disponible y hagan uso de los elementos de protección necesarios para la realización de cada labor, se informe y se capacite sobre el manejo de herramientas, uso de agroquímicos, manipulación de alimentos, derecho laboral, se realicen talleres de psicología y se les dé participación a los trabajadores mediante el derecho de opinar y denunciar las acciones administrativas con las que no están de acuerdo.

A su vez, la agricultura presenta la tendencia a generar una producción limpia para obtener una fruta más sana, que es la razón por la cual el mercado europeo prefiere pagar un dólar más por cada caja de banano que se consume. En concordancia con este comercio justo, se restringe en estos sistemas productivos la aplicación de herbicidas y se establecen las coberturas nobles para desplazar arvenses competitivas, asimismo se exige que los trabajadores estén protegidos, consuman agua potable, tengan acceso a las duchas, tanto para aseo personal como en caso de accidentes por derrames; en general se realiza un trabajo que vela por la integridad y calidad de vida de todos los trabajadores, se obtiene una fruta que viene de una producción que evita el exceso de agroquímicos y con el incremento de un dólar por caja permite ganar tanto a los productores como a los trabajadores. Es factible considerar, que bajo el sistema de manejo que se ha llevado a cabo en esta finca durante los últimos tres años, los embolsadores demuestren estabilidad en la actividad de la colinesterasa como se expresa en la Tabla 4.

Colinesterasa eritrocitaria, grupo técnico (D). Como parámetro comparativo, se realizaron las pruebas de colinesterasa en el grupo de apoyo técnico que labora en la comercializadora, haciendo referencia a ingenieros y administradores. Quienes participaron de esta evaluación, son profesionales en el campo de la agricultura y por lo tanto se desempeñan en diferentes labores del agro, por esta razón pueden estar en contacto permanente con la gran variedad de agrotóxicos que se emplean en la zona. Los resultados de los 
exámenes, expresan valores normales del nivel de colinesterasa con un caso en el nivel límite.

Al comparar los valores de colinesterasa de este grupo técnico con los embolsadores de cada una de las fincas, el primero no exhibe alteraciones de colinesterasa, mientras que en los embolsadores hay subnormalidades en algunos valores durante los dos últimos años. Se considera que la diferencia se debe al permanente contacto con el clorpirifos al manipular constantemente las bolsas de campo y, a su vez, al período de tiempo que llevan realizando esta labor, razón por la cual los embolsadores son el grupo más vulnerable a través del tiempo.

Otros agroquímicos en la producción de banano. Como parte complementaria al desarrollo de esta investigación, se hace necesario destacar que en la producción de banano se emplea otra serie de agroquímicos que contribuyen con el manejo de la producción como:

Tabla 4. Agroquímicos implementados en la producción de banano

\begin{tabular}{|c|c|c|c|c|}
\hline $\begin{array}{l}\text { CLASIFICACION } \\
\text { AGROQUIMICOS }\end{array}$ & $\begin{array}{c}\text { NOMBRE } \\
\text { COMERCIAL }\end{array}$ & $\begin{array}{c}\text { INGREDIENTE } \\
\text { ACTIVO }\end{array}$ & $\begin{array}{c}\text { CATEGORIA } \\
\text { TOXICOLOGICA }\end{array}$ & MODO DE ACCION \\
\hline \multirow{2}{*}{ Fungicidas poscosechs } & Magnste $75 \mathrm{SP}$ & Imszani| & II & Sistémico \\
\hline & Mertect $20 \mathrm{SL}$ & Tiabendazole & IV & Sistémico \\
\hline \multirow{2}{*}{ Fungicidas foliares } & Control 500 & Clorotalonil & 1 & Contscto \\
\hline & Mancozeb 80 WF & Manacozeb & III & Contacto \\
\hline \multirow{4}{*}{ Herbicidas } & Gramoxone SL & Parsquat & 1 & Contscto no selectivo \\
\hline & Glifosol & Glifosato & IV & $\begin{array}{c}\text { Amplio espectro no } \\
\text { selectivo }\end{array}$ \\
\hline & Fingle $S \mathrm{~L}$ & $\begin{array}{l}\text { Glufosinato de } \\
\text { amonio }\end{array}$ & IV & Contscto no selectivo \\
\hline & Reglone SL & Dicust & II & Contacto no selectivo \\
\hline \multirow{2}{*}{ Plaguicidas } & Lorsben $4 \mathrm{EC}$ & Clorpirifos & III & Amplio espectro \\
\hline & Lorsben $2.5 \% \mathrm{DP}$ & Clorpirifos & III & Amplio espectro \\
\hline
\end{tabular}

Fuente: Esta investigacion.

La aplicación de herbicidas. Para el control de arvenses se utiliza glifosato como ingrediente activo de productos comerciales como Roundup 747 y otras marcas. Para el manejo de la plantación, se realizan ciclos de aplicación cada cuatro semanas. Implica que un trabajador realiza la labor que corresponde a la preparación de la mezcla y la aplicación del producto en el campo, y permanece en contacto directo con estos agroquímicos.

Proceso poscosecha. Durante el proceso poscosecha de la fruta, se emplean fungicidas como Rally (ingrediente activo Myclobutanil, Triazol) y Amistar [ingredientes activos Azoxistrobina 20\% p/v (200 $\mathrm{g} / \mathrm{L})$ ], el ingrediente activo Azoxistrobina pertenece al grupo químico 
metoxicrilatos y el ingrediente activo Difenoconazol 12,5\% p/v (125 $\mathrm{g} / \mathrm{L}$ ) pertenece al grupo de los triazoles. Estos productos se aplican para la protección de la fruta con el propósito de evitar enfermedades como pudrición de la corona, y contribuyen con la protección en los períodos poscosecha, comercialización, hasta consumo de la fruta en lugares de destino. En el proceso poscosecha participan entre 15 y 30 trabajadores, lo cual depende del tamaño de la finca y del volumen de fruta proyectado en el día; cada una de estas personas puede estar expuesta, en cualquier momento, al contacto directo con estos fungicidas.

Fumigaciones aéreas. Se emplean fungicidas sistémicos y de contacto como Baycor (ingrediente activo Bitertanol, grupo químico triazol), Bravonil (ingrediente activo Chlorothalonil $720 \mathrm{~g} / \mathrm{L}$, grupo químico cloronitrilo), Dithane (Mancozeb, grupo químico ditiocarbamatos), entre otros. Es la actividad fitosanitaria más compleja en la producción de banano, puesto que se realizan aplicaciones aéreas cada dos semanas cubriendo las fincas bananeras de toda la región de Urabá, esto implica que un gran número de trabajadores y una apreciable población se encuentren expuestos permanentemente al contacto directo con estos fungicidas, lo que se genera por deriva del producto durante la aplicación al cultivo.

Frente a este panorama, las comercializadoras presentes en la zona, adoptan un programa de vigilancia epidemiológica en el cual se indaga a fondo la problemática presente. Dado que en la agroindustria bananera aún no se cuenta con evaluaciones de higiene al ambiente que incluyan: muestreos, cálculos estadísticos y resultados de productos utilizados en el proceso, con los cuales se determinen las áreas expuestas, se emplean solo como criterio la caracterización de los oficios de alta exposición realizados por las personas y el tipo de producto que manipula.

En la zona de Urabá el manejo y control de la Sigatoka negra (Mycosphaerella fijiensis), se determina bajo el concepto de las compañías de fumigación aérea, quienes a través de un grupo técnico especializado, definen las aplicaciones rotativas de los productos en todas las fincas bananeras. De esta manera, para controlar el desarrollo de la enfermedad, la fumigación aérea se realiza a través de aplicaciones calendarizadas o programadas durante el año; cubriendo toda la zona. En la actualidad se están aplicando 30 ciclos de fungicidas, lo cual explica que se realicen fumigaciones cada dos semanas y algunas veces cada semana. Las evaluaciones de campo son realizadas por los supervisores técnicos de las compañías de fumigación, sin embargo el concepto de la aplicación fungicida está basado en la programación cíclica de los productos que se requieren aplicar al año, esto quiere decir que las aplicaciones de los fungicidas no se realizan en función del desarrollo de la enfermedad, sino que ya existe una programación con la que estas compañías consideran que garantizan el control de la Sigatoka en las plantaciones. 
Tabla 5. Manejo de los agroquímicos implementados en la producción de banano

\begin{tabular}{|c|c|c|c|c|c|c|}
\hline $\begin{array}{c}\text { NOMBRE } \\
\text { COMERCIAL }\end{array}$ & $\begin{array}{l}\text { INGREDIENTE } \\
\text { ACTIVO }\end{array}$ & $\begin{array}{l}\text { EXAMEN A } \\
\text { REALIZAR }\end{array}$ & $\begin{array}{l}\text { FORMA DE } \\
\text { APLICACION }\end{array}$ & $\begin{array}{l}\text { FRECUENCIA DE } \\
\text { APLICACION }\end{array}$ & $\begin{array}{l}\text { PERIODO } \\
\text { DE } \\
\text { CARENCIA }\end{array}$ & $\begin{array}{l}\text { PERIODO DE } \\
\text { REINGRE SO }\end{array}$ \\
\hline Magnate $75 \mathrm{SP}$ & Imszail| & & Manual & Semengl & 0 & 0 \\
\hline Mertect $20 \mathrm{SL}$ & Tigbendgzole & & Manual & Semangl & 0 & 0 \\
\hline Control 500 & Clorotalonil & & $\begin{array}{l}\text { Aéres y } \\
\text { terrestre }\end{array}$ & $\begin{array}{l}\text { Cads } 45 \text { dias en } \\
\text { rotación con otros } \\
\text { fungicidas }\end{array}$ & 0 & $\begin{array}{l}\text { Al secarse el } \\
\text { producto }\end{array}$ \\
\hline Mancozeb 80 WP & Mancozeb & & $\begin{array}{l}\text { Aéres y } \\
\text { terrestre }\end{array}$ & Cada 20 días & 0 & $\begin{array}{c}\text { Al secarse el } \\
\text { producto }\end{array}$ \\
\hline Grsmoxone SL & Parsquat & & Manus| & Cads 40 dias & 0 & 0 \\
\hline Gifosol & Glifossto & & Manus| & Cads 40 dias & 24 horgs & 0 \\
\hline Fingle SL & $\begin{array}{l}\text { Glufosingto de } \\
\text { amonio }\end{array}$ & & Manual & Cads 40 dias & 0 & 0 \\
\hline Reglone SL & Dicust & & Manual & Cads 40 dias & 0 & 0 \\
\hline Lorsban 4 EC & Clorpinfos & $\begin{array}{c}\text { Colinestersss } \\
\text { plasmátics } \\
\text { eritrocitics }\end{array}$ & Manual & $\begin{array}{c}\text { Semangl con el } \\
\text { embolse }\end{array}$ & 0 & 0 \\
\hline Lorsbsn $2,5 \% \mathrm{DP}$ & Clorpirifos & $\begin{array}{l}\text { Colinestersss } \\
\text { plssmátics } \\
\text { eritrocítics }\end{array}$ & Manus| & $\begin{array}{l}\text { Esporádicamente } \\
\text { dos veces al anio }\end{array}$ & 0 & 0 \\
\hline
\end{tabular}

Fuente Esta investigacion.

Tabla 6. Población expuesta a plaguicidas de acuerdo con la labor que desempeña

\begin{tabular}{|l|l|}
\hline \multicolumn{1}{|c|}{ LABOR } & \multicolumn{1}{|c|}{ DESCRIPCION } \\
\hline Preparador de mezcla & $\begin{array}{l}\text { Trabajador encargado de preparar las mezclas de los } \\
\text { fungicidas, para la protección de la fruta en el proceso } \\
\text { poscosecha }\end{array}$ \\
\hline Almacenista & $\begin{array}{l}\text { Trabajador encargado de recibiry entregarlos insumos en el } \\
\text { lugar de almacenamiento }\end{array}$ \\
\hline Coordinador de empacadora & $\begin{array}{l}\text { Trabajador encargado de dirigirel proceso poscosecha de la } \\
\text { fruta }\end{array}$ \\
\hline Fumigador & $\begin{array}{l}\text { Trabajador encargado de realizar las aplicaciones terrestres } \\
\text { de fumigación para el control de la sigatoka, en las área de } \\
\text { Ios linderos }\end{array}$ \\
\hline Embolsador & $\begin{array}{l}\text { Trabajador encargado de ubicarla bolsa en los racimos, para } \\
\text { la protección de la fruta }\end{array}$ \\
\hline Abrebolsa & $\begin{array}{l}\text { Trabajador encargado de quitar la bolsa que cubre el racimo, } \\
\text { antes de ser procesado }\end{array}$ \\
\hline Sellador & $\begin{array}{l}\text { Trabajador encargado de identificar los gajos de banano, con } \\
\text { un sello propio dela comercializadora, en calidad de fruta de } \\
\text { exportación }\end{array}$ \\
\hline
\end{tabular}

Fuente: Esta investigacion.

Durante los dos últimos años se ha retirado de la explotación bananera el Paraquat (categoría toxicológica I) ingrediente activo del herbicida gramoxone, que se utilizaba para controlar el crecimiento de arvenses; el producto fue retirado por exigencia del mercado europeo donde el agroquímico tiene restricciones por su categoría toxicológica. En Colombia ninguna norma prohíbe ni restringe su uso en los diversos sistemas de producción agrícolas y solo se prohíbe la aplicación aérea del producto según Resolución 3028 del 15 de agosto de 1989 expedida por el ICA. 


\section{Ruta toxicológica en la manipulación de la bolsa impregnada con clorpirifos}

Durante el trabajo de campo, se realizó un seguimiento sobre la producción y manipulación de las bolsas de campo empleadas en la zona, para la protección de la fruta, y se describe a partir de la siguiente ruta de exposición al clorpirifos:

\section{Fábrica de plástico}

En la región de Urabá se encuentra la fábrica de plástico de Banacol, que produce el volumen de plástico y fibra que necesitan las comercializadoras de banano ubicadas en la zona. Los materiales requeridos para la producción de bolsa de campo, al igual que la producción de fibra, son materias primas importadas (polipropileno y polietileno), provenientes de los subproductos de los hidrocarburos o derivados del petróleo, de esta forma los materiales son fundidos y mezclados por procesos térmicos a través de un sistema mecánico elaborándose grandes cantidades de bolsa y fibra al día. Las cantidades de bolsa que se producen, no alcanzan a satisfacer los volúmenes requeridos para cubrir la demanda en la zona bananera, razón por la cual se importan de otros países.

\section{Proveedores de bolsa de campo}

Cuando la fábrica produce los volúmenes de bolsa requeridos por las comercializadoras, son distribuidas por diferentes proveedores quienes se encargan de suministrar a cada finca la cantidad de bolsas de acuerdo con la semana solicitada por la dirección comercial; la cantidad de bolsa que una finca requiere está basada en los promedios de embolse de fruta que se realizan cada semana, de esta manera se controlan las cantidades exactas de bolsa de campo que cada finca debe manejar con base en los inventarios de fruta.

\section{Manejo de la bolsa en las fincas}

Las bolsas de campo son retiradas de los puntos de venta por los camiones de la comercializadora, y a su vez son llevadas a cada finca de manera independiente sin ser mezcladas con otros insumos o productos. Cuando el camión llega a la finca, el conductor hace la entrega del insumo de manera personal al almacenista, quien recibe las bolsas contando los rollos y registrando el ingreso del producto con su respectiva remisión, para asentar la información en el kárdex y otros registros necesarios. De esta manera, se le hace seguimiento y control a cada insumo que ingresa a la finca. Los rollos de bolsa son almacenados en una bodega de agroquímicos, bajo las respectivas normas de seguridad (iluminación, ventilación, ubicación). De allí, el material es entregado por los almacenistas a cada trabajador que realiza la labor del embolse, siguiendo un procedimiento de entrega con adecuado registro en un documento de: la cantidad de bolsas entregadas, el nombre del trabajador y la hora. En promedio se entregan 250 bolsas a cada trabajador en horas de la mañana y en las horas de la tarde 150. 


\section{Manipulación de la bolsa por el trabajador}

El trabajador, antes de iniciar la labor y recibir la bolsa de campo, debe prepararse y aprovisionarse a primera hora de la mañana de los objetos de protección personal y la herramienta. Cuando el trabajador cumple con los anteriores requisitos, procede a recibir las bolsas de campo que son entregadas por el almacenista de la finca, firma el correspondiente registro y se dirige a la plantación bananera, para ejecutar el embolse el cual, basado en las instrucciones del administrador de la finca, consiste en que el trabajador debe ubicar la bolsa teniendo en cuenta dos tipos de embolse: 1) Embolse prematuro: es aquel en el cual se pone la bolsa cuando descuelga la bellota, sin haber abierto las manos que constituyen el racimo. 2) Embolse presente: se pone la bolsa cuando el racimo tiene dos o tres manos abiertas. Este embolse se realiza solo donde la incidencia de plagas no ha afectado la calidad de la fruta. Un trabajador tiene un promedio de embolse comprendido entre 350 y 400 racimos al día, y permanece en contacto con las bolsas de campo desde las 6 de la mañana hasta las 4 de la tarde. Realiza la labor dos veces a la semana; lunes y jueves o martes y viernes.

Cuando el embolsador termina su jornada de trabajo, procede a quitarse la ropa de protección personal y a bañarse; para ello cuenta con las instalaciones necesarias para su aseo personal. La ropa que fue utilizada en el día es lavada por la persona encargada del aseo de todas las instalaciones de la finca, quien lava toda esta ropa dentro de la finca utilizando una lavadora; los elementos de protección implementados para esta persona son: guantes de nitrilo largos, botas y un delantal de plástico que protege el cuerpo de la persona de la humedad. Las aguas provenientes de este lavado, son conducidas por un sistema de tubería que las lleva hasta un pozo profundo, al cual llegan todas las aguas residuales que se producen en la finca como las aguas negras producto de la cocina y de los baños. El pozo dispone de varios filtros, lo que hace que las aguas permanezcan en un proceso de purificación desde que ingresan al pozo hasta que salen de este sitio para integrarse con los cauces de agua naturales, que circulan por los diferentes canales que se trazan en una finca bananera; finalmente, estas aguas llegan a los ríos que desembocan en el mar. Para el manejo de estas aguas contaminadas, se realiza una evaluación al año sobre la residualidad de las aguas a la entrada y a la salida del pozo, para determinar la eficiencia de la remoción de residuos orgánicos y la carga contaminante. Mediante la toma de estas muestras analizadas en un laboratorio, se determina el grado de contaminación que se está generando en las fincas bananeras.

\section{Manejo del residuo de bolsa}

El racimo de banano, se cosecha en el campo cuando cumple la edad y las especificaciones requeridas para los embarques; el procedimiento conlleva el corte del racimo en la mitad del vástago y posteriormente la ubicación de la fruta en garruchas que conducen los racimos con su correspondiente bolsa a lo largo de un cable, que se dirige a la empacadora; es en este lugar donde se realiza el tratamiento poscosecha. De esta manera, cada racimo llega a las 
empacadoras, donde hay un trabajador encargado de retirar las bolsas de estos racimos para que puedan ser procesados. Las bolsas se recolectan durante el proceso, en canecas y posteriormente se almacenan en una bodega exclusiva para su manipulación, y de allí son entregadas a una cooperativa que les da diferentes usos a este material. Se requieren inicialmente dos trabajadores, el primer operario elige el racimo adecuado y corta la planta, y el segundo operario recibe en sus hombros, sobre una cuna el racimo cortado; posterior a esto, el racimo es llevado hasta el cable donde otro operario lo ubica sobre una garrucha constituyendo una fila de 20 a 25 racimos, para ser transportados hacia la empacadora por un último operario. Para realizar esta labor de cosecha, los trabajadores utilizan como implementos de protección la dotación personal, haciendo referencia a las botas de caucho, la sudadera y la camisa de cualquier tipo. Realmente no se evidencia ningún sistema de protección personal durante el proceso de la cosecha; el corte de los racimos se realiza por un grupo de cuatro trabajadores y únicamente la persona que transporta los racimos hasta la empacadora utiliza el casco como su implemento de protección. Se observó que los trabajadores que realizan la cosecha se encuentran en contacto directo y permanente con la bolsa de campo, desde que se corta el racimo de la planta hasta que es procesado en las empacadoras.

Los racimos llegan a la empacadora, en donde se encuentra una persona encargada de quitar la bolsa que cubre cada racimo, esta persona utiliza como medio de protección: casco, botas, sudadera y camisa. Los operarios encargados de quitar y recoger la bolsa no utilizan los guantes de nitrilo, generándose un contacto directo de la piel con estas bolsas. Durante la realización de esta práctica se evidencian algunos residuos de bolsa que se quedan en el suelo, cerca de la empacadora. Algunos de estos residuos se recogen y se almacenan, pero estos pequeños fragmentos se pueden dispersar con facilidad en cualquier parte de la finca convirtiéndose en pequeños focos de contaminación. Es muy común encontrar pedazos de estas bolsas enterradas en el área de producción.

\section{Manejo de la bolsa por las cooperativas}

La bolsa de campo representa una fuente de contaminación latente, debido al contenido de clorpirifos, por esta razón es colectada sin sufrir procesos de lavado para evitar contaminación de las fuentes hídricas. Las fincas son la fuente primaria de recolección de las bolsas tratadas con clorpirifos, de allí se recolectan en camiones por parte de las cooperativas encargadas de cubrir gran parte de la zona en cuanto a la recolección del plástico; luego se dirigen a las instalaciones donde se prensan, y posteriormente se conforman pacas de 150 kilos. Estas pacas son empleadas en la industria para la fabricación de mangueras, escobas y otras herramientas e igualmente se usan en minería. 


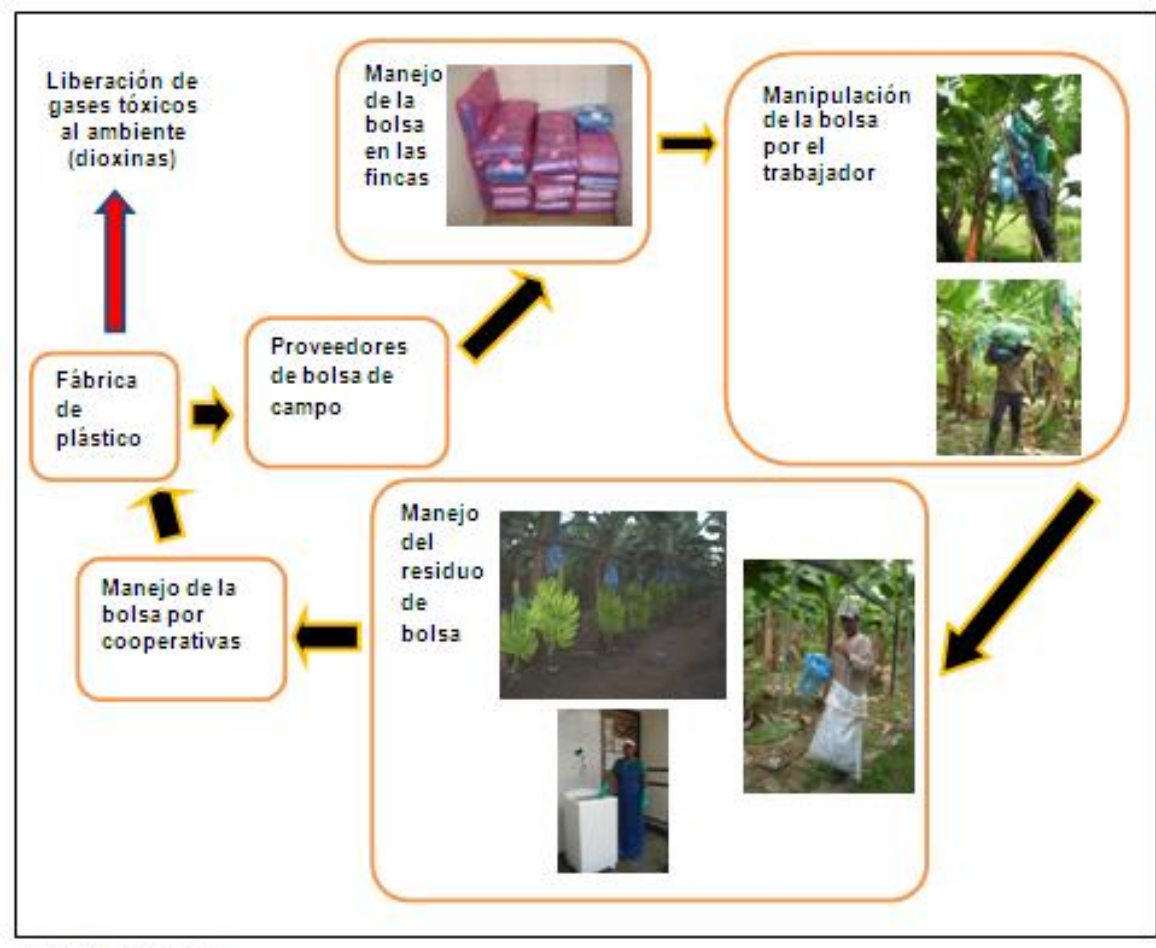

Fiente Esta in estogeion

Gráfico 3. Ruta tóxics

\section{DISCUSIÓN}

A pesar de la existencia de argumentos, basados en otras investigaciones y parámetros legales, que manifiestan el grave deterioro de la salud humana cuando se expone al trabajador al contacto permanente con el clorpirifos, en una población tan joven como la de los trabajadores de Urabá se determinó que algunas personas exhiben alteraciones en su historial clínico. Se usa un solo criterio de medida en el manejo médico (un único examen no muy específico sobre el nivel de colinesterasa y la reubicación al encontrar alteraciones), lo que pone en cuestionamiento la exposición permanente y de largo plazo de los operarios de campo al especializarles en la aplicación de una suma de agroquímicos y sus mezclas, con los consecuentes efectos en su salud.

Los exámenes de colinesterasa realizados en el grupo de 23 personas, demostraron actividad subnormal a través del tiempo en cinco trabajadores en una de las cuatro valoraciones realizadas durante el período 2008 a 2009 y tres más estuvieron en el nivel límite, incluido el administrador. El tratamiento al cual fueron sometidos (los cinco operarios), fue la reubicación inmediata de su labor para desempeño en otro trabajo que no implicara la manipulación de agroquímicos por cuatro meses mientras tanto se realizó la siguiente prueba de colinesterasa. En este punto se definió si el trabajador continuaba reubicado o si por el contrario volvía a su actividad de embolsador. A partir de este procedimiento, se considera necesario en este ejercicio de investigación, que a los trabajadores que presentan alteraciones en cualquiera de sus valoraciones, debería realizárseles un segundo examen con mayor 
profundidad (por ejemplo el ensayo cometa en eritrocitos) que juzgue las causas y determine con exactitud su estado de salud.

Es evidente que, frente al tiempo de exposición y la protección mediante un vestido de labor todavía insuficiente, hay indicios de intoxicación aguda en todos los trabajadores y elementos de intoxicación crónica que se hacen más incidentes por el tipo de labor, que no solo queda en dos días de trabajo con embolsado, sino que se continúa con otros procesos de manipulación del plástico tratado con clorpirifos a lo largo de la semana, y que se traducen en efectos crónicos.

Asaltan las siguientes preocupaciones:

1) Los exámenes de colinesterasa realizados bajo el método Michel están fundamentados en rangos de valores estandarizados y generalizados en poblaciones de otros países, por lo cual se asume que el método fue adaptado bajo el mismo criterio para las poblaciones colombianas. El procedimiento no enfatiza la situación clínica de cada paciente de manera particular, y la salud de estas personas se rige única y exclusivamente por los resultados de este método. En las comercializadoras no se tiene en cuenta el historial clínico ni los antecedentes de salud que estos trabajadores han desarrollado en otras comercializadoras diferentes. A su vez, los operarios no solo están expuestos al clorpirifos sino a una mezcla de productos agrotóxicos y por esta razón las pruebas para determinar los daños deben ser diferentes a las de colinesterasa; se aconseja, por lo tanto, hacer pruebas con biomarcadores. El panorama muestra ausencia de una instancia especializada y personal formado en medicina ocupacional.

2) Bajo el precepto de la certificación de las fincas bananeras, las empresas comercializadoras de banano establecen estrategias para complacer a las empresas transnacionales, que les obligan a garantizar la salud ocupacional. Esto quiere decir, que las comercializadoras cumplen frente a las normas laborales con los procedimientos necesarios, entre ellos realizar los exámenes de colinesterasa cada cuatro meses, y que de acuerdo con los resultados, el procedimiento sanitario como empresa solo tiene en cuenta la reubicación del trabajador cuando el obrero de campo está expuesto al plaguicida y solo hasta este punto llega la responsabilidad empresarial; el trabajador asume los riesgos en su salud y la trascendencia de los mismos. Este sector no exhibe voluntad para reconocer y prevenir enfermedades ocupacionales a tiempo, y cuando el riesgo de contaminación por clorpirifos se presenta, se le da un manejo solo legal.

3) Los productores bananeros son apáticos a la transferencia de tecnología que se realiza en la zona, en donde se ha demostrado en fincas experimentales que la protección de la fruta puede realizarse con bolsas sin contenido de clorpirifos a menor precio, demostrando excelentes resultados en la calidad de la producción. Sin embargo, las decisiones son tomadas por los propietarios quienes miran con desconfianza las nuevas alternativas en el manejo agrario, y por esta razón se casan con las técnicas antiguas de producción. 
4) Desde que se produce la bolsa de campo hasta que cumple todo su ciclo, es manipulada por un gran número de personas que entran en contacto diariamente con el contenido del clorpirifos que contiene la bolsa. De esta manera, no se descarta la posibilidad de que otras personas que no están realizando la labor del embolse, se vean afectadas por el clorpirifos. Se considera con este argumento, que los exámenes de colinesterasa no deberían limitarse a los embolsadores exclusivamente, y por lo tanto debería crearse un programa que involucre más personas, para minimizar los riesgos en la salud de los trabajadores que se desempeñan en torno a la producción de banano.

El sector bananero juega un papel importante en la economía, especialmente en Urabá donde todas las actividades productivas giran en torno al negocio de producir y exportar banano. Aunque se desarrollan otros renglones productivos diferentes al banano como plátano, arroz, maíz, ganadería, hay una alta dependencia económica de la actividad bananera. Gran parte del manejo adecuado de los plaguicidas se debe basar en la capacitación y educación ambiental y sanitaria, que redunde en la prevención y minimización de riesgos asociados al uso y manejo de plaguicidas. En este sentido, es importante definir un plan nacional ambiental para orientar y optimizar los recursos, en el cual la coordinación institucional y la divulgación efectiva sobre los impactos generados por los plaguicidas permitan en un plazo muy cercano concientizar a la población rural y a los trabajadores sobre estos productos. Para ello, se debe trabajar de manera conjunta y coordinada entre el Estado, la comunidad, las organizaciones no gubernamentales y el sector privado.

Colombia es un país que por su posición geográfica presenta unas condiciones particulares climáticas y de alta biodiversidad, las cuales se reflejan en numerosas plagas que atacan a los cultivos agrícolas, pero igualmente brindan la oportunidad de disponer de agentes naturales para el control biológico. En este sentido, el país tiene el reto de manejar y controlar las plagas con criterios científicos racionales que propendan por una agricultura sostenible. Al respecto, vale la pena reseñar los esfuerzos que vienen adelantando varios países con condiciones económicas, culturales y geográficas diferentes a las colombianas, en el diseño e implementación de políticas que buscan la racionalización en el uso de plaguicidas pensando en la protección del medio ambiente y la competitividad del sector productivo agropecuario, como es el caso de Suecia que desde 1986 inició un plan de reducción de los riesgos al medio ambiente y a la salud de las personas; el Reino Unido desde 1986 lanzó un plan para minimizar el uso de plaguicidas y sus riesgos asociados; Dinamarca desde 1990 arrancó con un plan de acción para la reducción de las aplicaciones de plaguicidas; y Holanda desde 1993 empezó con un plan de protección de cultivos en varios años. 


\section{REFERENCIAS}

- Amador, M. y Astorga, Y. (2006). Foro Emaús. Banano que envenena. Recuperado de http://www.foroemaus.org/espanol/ambiental/04

- ATSDR (Agencia de Sustancias Tóxicas y el Registro de Enfermedades). (1997). Departamento de Salud y Servicios Humanos de los EE.UU., Servicio de Salud Pública. Resumen de salud pública, 1997. Clorpirifos caso \# 2921-88-2. Recuperado de http:// www.atsdr.cdc.gov/es

- Colombia, Ministerio de Salud, Decreto 1843 de 1991, Por el cual se reglamentan parcialmente los títulos IIIV, VI, VII y XI de la Ley 09 de 1979 , sobre el uso y manejo de plaguicidas.

- Colombia, Ministerio de la Protección Social, Decreto 3518 de octubre 9 de 2006, Por el cual se crea y reglamenta el Sistema de Vigilancia en Salud Pública y se dictan otras disposiciones. Diario Oficial, Año CXLII, No. 46.417 de 10 de octubre de 2006, pp. 6-13.

- Díaz, P. y Salinas, S. (2002). Plaguicidas, tabaco y salud: El caso de los jornaleros huicholes, jornaleros mestizos y ejidatarios en Nayarit, México.

Recuperado

de http://www.huicholesyplaguicidas.org/documentos/estudio_epid emiologico.pdf

- Dow AgroSciences (1998). Clorpirifos - Norteamérica. Acerca del clorpirifos. Recuperado

de http://www.dowagro.com/chlorp/chlorp_es/na/about/

- Espinal, C. F., Martínez, H. J. y Peña, Y. (2005). La Cadena del Banano en Colombia una mirada global de su estructura y dinámica 1991-2005. Ministerio de Agricultura y Desarrollo Rural. Observatorio Agrocadenas Colombia. Recuperado de http://www.agrocadenas.gov.co

- Estrada, D. (2005). Intoxicados demandan restringir plaguicidas. Recuperado de http://www.eco2site.com/news/Dic-05/intoplagui.asp

- Hurtado, C. M. y Gutiérrez, M. (2005). Enfoque del paciente con intoxicación aguda por plaguicidas organofosforados. Rev Fac Med Univ Nac Colomb, 53(4), 244-258.

- Memorias Expoagricultura. (2001). Tendencia de la plasticultura bananera. VI Semana de la Agricultura, 6-8 Junio, de 2001. UNIBANApartadó.

- Monterroso, A. y Ferreira, W. (2006). Agrotóxicos en Bella Unión. Tejiendo redes de salud comunitaria. Recuperado de http://webs.chasque.net/ rapaluy1/publicaciones/Agrotoxicos_B ella_Union.pdf

- Sierra, L. E. (1993). El cultivo del banano. Producción y comercio. Medellín: Gráficas Olímpica.

- Telasky, K. (2007). Información para trabajadores agrícolas. Monitoreo de la colinesterasa para personas que manipulen pesticidas. Washington State Department of Labor \& industries. Recuperado de http://www.Ini.wa.gov/Safety/Topics/Atoz/Cholinesterase/files/C HeFactSheet-Spanish.pdf

- Varona, M., Henao, G., Lancheros, A., Murcia, A., Díaz, S., Morato, R., Morales, L., Revelo, D. y De Segurado, P. (2007). Factores de exposición a plaguicidas organofosforados y carbamatos en el departamento del Putumayo. Biomédica, 27(3), 400-9. 
- Velásquez, J. A. y Giraldo, P. A. (2005). Posibilidades competitivas de productos prioritarios de Antioquia frente a los acuerdos de integración y nuevos acuerdos comerciales. Secretaría de Productividad y Competitividad Departamento de Planeación. Recuperado

http://www.gobant.gov.co/organismos/scompetividad/doc

- Wesseling, C., Aragón, A., Rojas, M., López, L., Blanco, L., Soto, A., Fúnez, A., Ruepert, C., Miranda, J. y López, I. (2005). Plaguicidas. Efectos del clorpirifos sobre el sistema nervioso de trabajadores bananeros en la Lima, Honduras. Salud y seguridad laboral en América Latina. III Conferencia sobre salud ocupacional y ambiental de las Américas 2005. "Integrando las Américas frente a los efectos de la globalización", 6-9 de febrero, 2005, Alajuela, Costa Rica. Arch Prev Riesgos Labor, 8(2): 69-91. Recuperado de http://www.scsmt.cat/Upload/TextComplet/1/1/116.pdf

Para citar este artículo: Aguirre-Buitrago, J. C., Narváez-González, S. C., Bernal-Vera, M. E. \& Castaño-Ramírez, E. (2014). Contaminación de operarios con clorpirifos, por práctica de "embolsado" de banano (Musa sp.) en Urabá, Antioquia. Revista Luna Azul, 38, 191-217. Recuperado de http://lunazul.ucaldas.edu.colindex.php?option=content\&task=v iew\&id=902 